\title{
Marketing Products With Wildlife: How to Make It Benefit Conservation
}

\author{
Alexander Braczkowski ${ }^{1,2,3,4 *}$, James R. Allan ${ }^{5}$, Kendall R. Jones ${ }^{6}$, Meganne Natali ${ }^{7}$, \\ Duan Biggs ${ }^{4,8,9}$ and Martine Maron ${ }^{1,3}$ \\ ${ }^{1}$ School of Earth and Environmental Sciences, The University of Queensland, Brisbane, QLD, Australia, ${ }^{2}$ School of Natural \\ Resource Management, Nelson Mandela University, George, South Africa, ${ }^{3}$ Centre for Biodiversity and Conservation \\ Science, The University of Queensland, Brisbane, QLD, Australia, ${ }^{4}$ Resilient Conservation, Centre for Planetary Health and \\ Food Security Griffith University, Nathan, QLD, Australia, ${ }^{5}$ Institute for Biodiversity and Ecosystem Dynamics (IBED), \\ University of Amsterdam, Amsterdam, Netherlands, ${ }^{6}$ Wildlife Conservation Society, Global Conservation Program, Bronx, NY, \\ United States, ${ }^{7}$ Institut du Droit de la Paix et du Développement, Université de Droit de Nice Côte d'Azur, Nice, France, \\ ${ }^{8}$ Department of Conservation Ecology and Entomology, Stellenbosch University, Stellenbosch, South Africa, ${ }^{9}$ Centre for \\ Complex Systems in Transition, School of Public Leadership, Stellenbosch University, Stellenbosch, South Africa
}

\section{OPEN ACCESS}

Edited by:

William J. McShea,

Smithsonian Conservation Biology Institute (SI), United States

Reviewed by:

Fred Van Dyke,

American Association of Retired Persons, United States Igor Khorozyan, University of Göttingen, Germany

*Correspondence: Alexander Braczkowski alexander.braczkowski@gmail.com

Specialty section:

This article was submitted to Animal Conservation,

a section of the journal

Frontiers in Conservation Science

Received: 05 January 2021 Accepted: 19 April 2021 Published: 22 June 2021

Citation:

Braczkowski A, Allan JR, Jones KR Natali M, Biggs D and Maron M (2021) Marketing Products With Wildlife: How to Make It Benefit Conservation. Front. Conserv. Sci. 2:649686. doi: 10.3389/fcosc.2021.649686
A key obstacle to wildlife conservation is a scarcity of funding. A recent paper [Courchamp, F., Jaric, I., Albert, C., Meinard, Y., Ripple, W. J., and Chapron, G. (2018). The paradoxical extinction of the most charismatic animals. PLoS Biol. 16:e2003997. doi: 10.1371/journal.pbio.2003997] illustrates how for-profit businesses' widespread use of threatened wildlife imagery could create complacency in the public about their conservation. A wildlife imagery royalty, whereby businesses that use threatened wildlife in their marketing pay a small percentage of their sales to the conservation of those species could be revolutionary for conservation funding. However, businesses are not currently compelled to support the protection of the species espoused in their products. We build upon the arguments presented by recent publications [Good, C., Burnham, D., and Macdonald, D. W. (2017). A cultural conscience for conservation. Animals 7:52. doi: 10.3390/ani7070052; Courchamp, F., Jaric, I., Albert, C., Meinard, Y., Ripple, W. J., and Chapron, G. (2018). The paradoxical extinction of the most charismatic animals. PLoS Biol. 16:e2003997. doi: 10.1371/journal.pbio.2003997] to explore limitations and a number of key pathways that may help bring a wildlife imagery royalty to fruition.

Keywords: wildlife imagery royalty, felid, funding, royalty, tax, legal personhood

\section{INTRODUCTION}

A key obstacle hampering biodiversity conservation is a lack of funding (McCarthy et al., 2012; Waldron et al., 2013; Box 1), driving scientists and conservation organizations to search for innovative funding mechanisms. Good et al. (2017) and Courchamp et al. (2018) have presented an example of the latter. They have proposed that businesses using the imagery of threatened wildlife in their marketing should contribute toward the conservation of those species. Good et al. (2017) suggested that a wildlife imagery royalty would herald a revolution in conservation funding. This idea is not unlike the one proposed by Jepson et al. (2011), who called on the film and media industry to contribute financially to the conservation of the species they film.

At a glance, the rationale for wildlife imagery royalties is akin to payment of license fees for merchandise; for example, a t-shirt manufacturer paying the singer Madonna for the rights to use her photograph or likeness on t-shirts (Courchamp et al., 2018). However, on closer inspection, the idea of businesses paying a fee for using images of wildlife opens up a Pandora's box of questions. Firstly, businesses generally exist for profit, not for altruistic reasons (Drucker, 1954; Friedman, 1970). Therefore, would companies or their shareholders actually care about the species their 


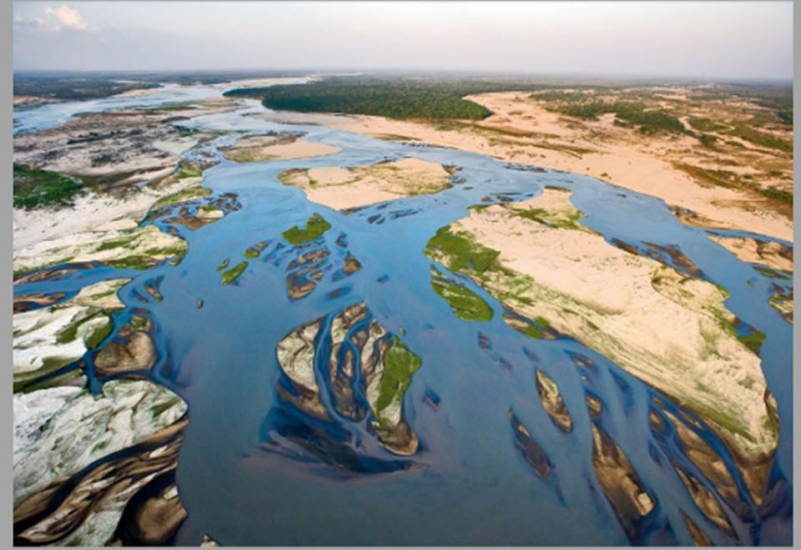

Some of Africa's countries and national parks (like Tanzania's Selous), which are considered key for African lion conservation, are also the ones which suffer the greatest funding shortfalls. The yellow spheres represent the top ten African range states with the largest contributions to the African lion's range and are adjusted in size in order to fit on the map. The numbers represent a ranking in terms of how underfunded a country is. Even though the two largest range states (Botswana and Tanzania) are the last in terms of their relative need, they still require 422 and 360 USD\$ million, respectively. Data from Lindsey et al. (2018). Image: @Steve Winter.

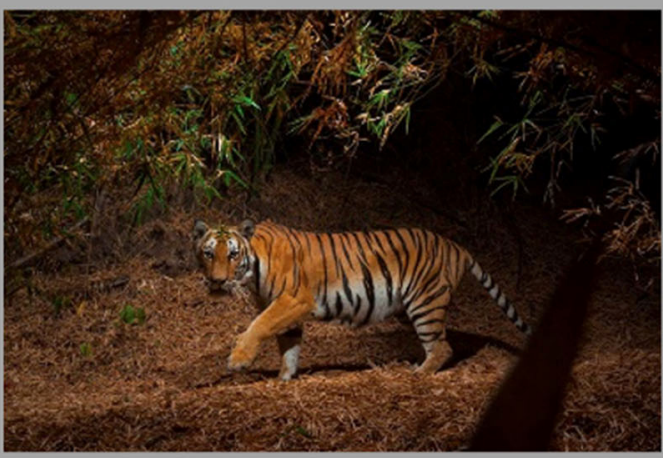

Data from 6057 donors in 119 countries show that environmental and animal welfare causes garner $16 \%$ of philanthropic effort. Data from Coad et al (2019) shows that $<25 \%$ of 2167 protected areas globally have adequate funding, staffing and resources to achieve conservation outcomes. Pie chart made using data from https://givingreport.ngo/. Image @Steve Winter.
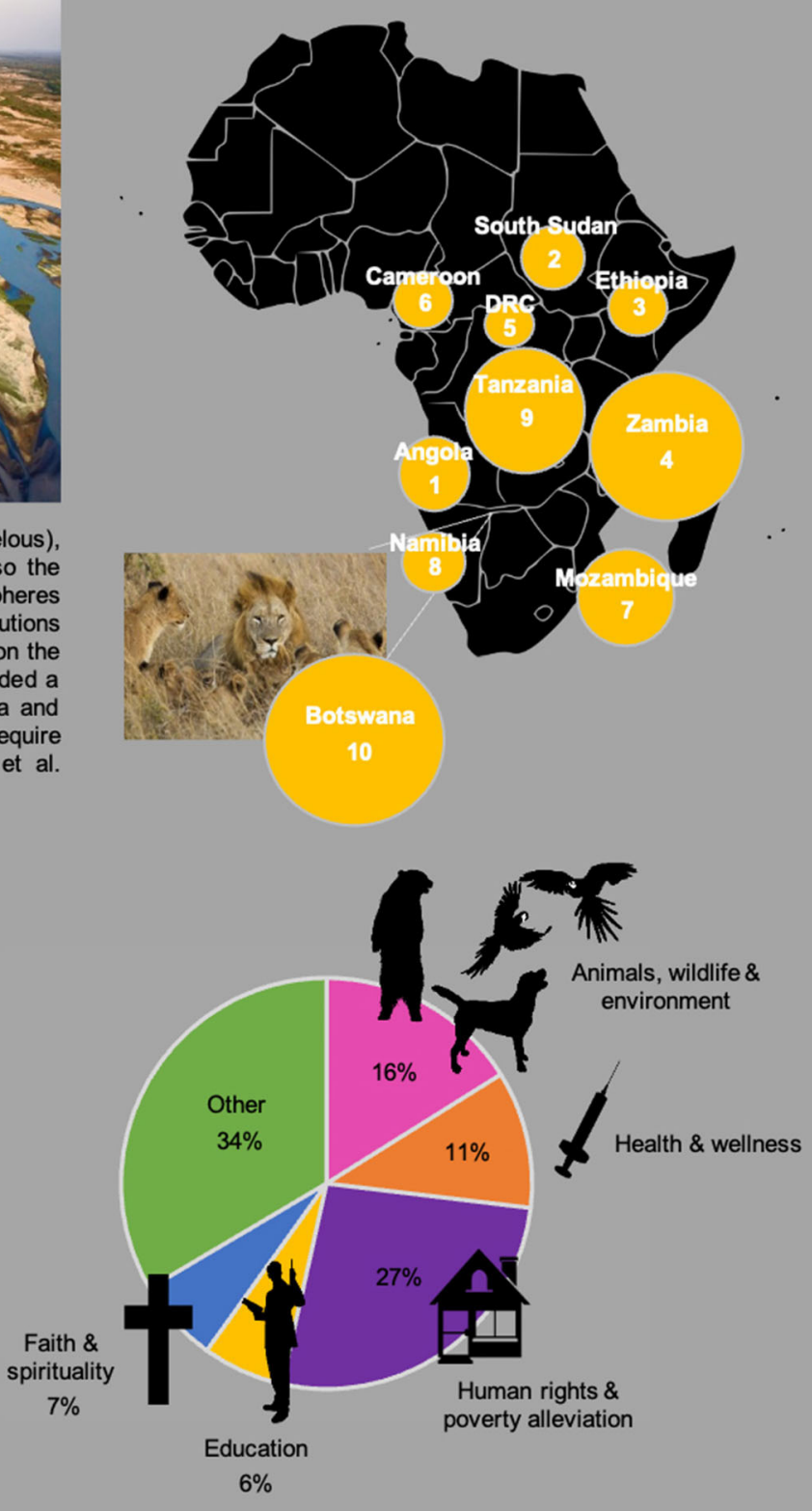

Box 1 | Funding deficits for protected area management and threatened species conservation are vast. Even the most charismatic large felids such as African lions Panthera leo and tigers Panthera tigris face severe funding shortfalls. Data from Lindsey et al. (2018) and Coad et al. (2019), and the Global Trends in Giving 2018 report (see http://rocklandcce.org/resources/2018-global-trends-in-giving-report; accessed 5 August 2019) illustrate this point.

products espouse enough to sign up for such an initiative? Ought there to be legal rights associated with the use of the imagery of a Bengal tiger Panthera tigris? And how far should this idea go-if Tiger Beer pays toward tiger conservation, should Apple Inc. pay proceeds to the conservation of threatened Malus species?

In our opinion, Courchamp et al. (2018) captured a powerful justification for such a royalty. They suggest that businesses, through their marketing, are creating a perception in members of the public that populations of wildlife are common and therefore not of conservation concern. The mechanism for this is the public's exposure to an abundance of iconic wildlife imagery in products and advertising. Courchamp and others cite this as a key reason why businesses should pay a fee to display these species on their products. In addition, many companies 

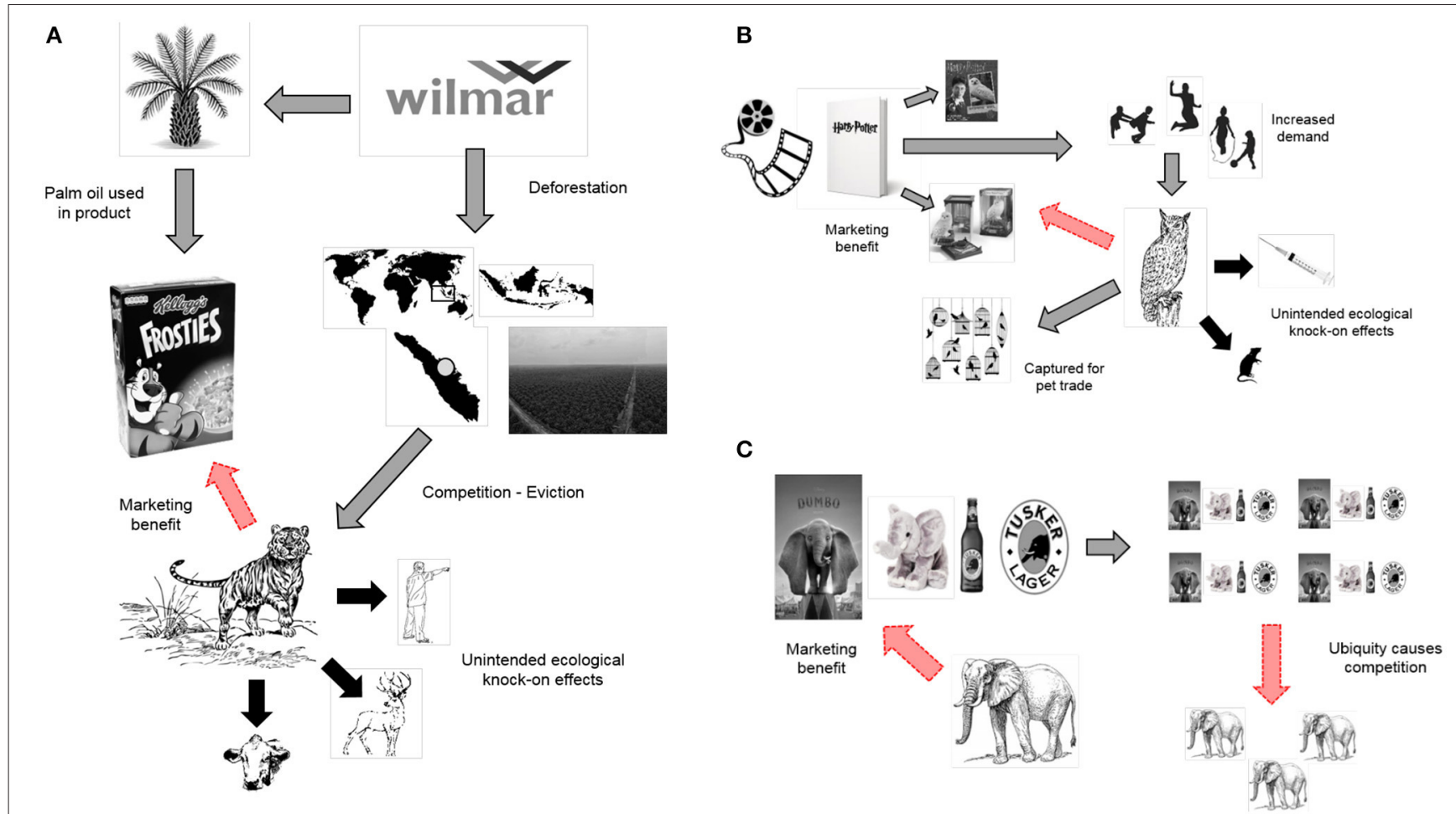

FIGURE 1 | Three examples of the mismatch between direct benefits accrued by companies in the use of threatened wildlife imagery and potentially negative effects exuded on those species by the companies. (A) This picture shows how the Kellogg's Company purchases palm oil from the Wilmar Group. The palm oil is sourced from Riau, Sumatra (Indonesia) - locally important for both its forests and tiger populations. Wilmar has been linked to deforestation and unsustainable palm oil production. Deforestation reduces suitable habitat for tigers, causes intraspecific strife, and may have numerous cascading effects on tiger prey, conflict with people and their livestock. Kellogg's uses tigers in their marketing campaigns and Tony the tiger has been the face of their Frosties cereal for over 65 years. (B) This figure shows an unintended effect caused by the dramatic rise in popularity of the Harry Potter franchise. Harry's owl, and others seen in the film are believed to have increased the demand for pet owls by children in Malaysia. The franchise, characterized by the movies, books, and merchandise benefited from the use of owls, however, increased exploitation is likely to have placed pressure on these top-order avian predators. (C) Illustrates the competition of a virtual population of elephants (used on beer bottles, in the recent Dumbo film and plush toys) for public attention. Courchamp et al. (2018) showed that knowledge of in situ wildlife population species status in the public is being dumbed down by the ubiquity of these virtual populations.

actually negatively impact the species whose images they use, either directly through habitat destruction, or indirectly through unintended anthropogenic effects (e.g., increased exploitation because of popularization in a film or book; Figure 1).

If conservationists and policymakers can agree that this justification holds merit, we can progress to asking how a legal basis for the implementation of such a royalty could be developed. Many companies voluntarily support conservation projects (see Supplementary Table 1), but a compelled royalty would likely be more stable than a reliance on corporate social responsibility (CSR) and philanthropy, which can be affected by market trends (Reich and Wimer, 2012). Some models already exist, for example, businesses in India that generate $>\$ 105$ million US\$ per year are compelled by law to pay $2 \%$ of their profits to charities (Singh and Verma, 2014). A compelled royalty for the use of wildlife imagery could help maintain funding continuity to conservation projects, a key determinant of successful recovery programs (Crees et al., 2016).

In this paper, we investigate if a wildlife imagery royalty is a thing of fantasy or has some chance of realization in the future via legal or policy mechanisms. Our paper builds upon Courchamp et al. (2018), who concluded their paper with a call for innovative interdisciplinary works to explore how such a payment mechanism might be constructed. Here, we present some preliminary thoughts on potentially useful institutional tools. We refer to recent legal personhood case successes for river, glacier, and broader nature rights globally (Charpleix, 2018; O’Donnell and Talbot-Jones, 2018; Pecharroman, 2018) and failures of cases for individual animal personhood for captive animals (e.g., chimpanzees Pan troglodytes and Asian elephant Elaphus maximus; Boyle, 2016; Staker, 2017) in the United States. We argue that although nature-based laws are making progress, their evolution and adoption is slow and would require significant changes to support a generalized wildlife imagery royalty.

We recommend two pathways that could allow for faster implementation of such a royalty. These include (1) a nationally instituted royalty on products bearing the images of threatened wildlife (and businesses recognized as threatening them) and (2) a certification mark (akin to Fairtrade or 1\% for the Planet), which would allow the bearers to display it on their products in exchange for a small royalty payment (and which itself is protected by copyright). To conclude, we use charismatic and highly threatened larger members of the Felidae (big cats) as 
a model to illustrate the immense potential for such schemes to augment funding for conservation and discuss potential unintended consequences of a wildlife imagery royalty.

\section{EXAMPLES OF HISTORIC WILDLIFE MARKETING IN BUSINESS AND BRANDING}

A "wildlife imagery royalty" has been discussed by academics and conservation non-government organizations (NGOs) for over 20 years. Baltz and Ratnaswamy (2000), for example, examined the number of tertiary education institutions in the USA contributing financially to the conservation of their tiger mascots under a program called Tigers for Tigers (2018).

There are also a plethora of recent examples of corporations and private companies collaborating with conservation NGOs to support the wildlife species used in their advertising, branding, and trademarks. Examples include Lacoste's TM partnership with the IUCN and the Save Your Logos initiative to fund crocodilian conservation (Lacoste, 2018) and the 2018 Commonwealth Games organizers raising US\$ 73,000 through the sale of the Borobi mascot for injured koalas Phascolarctos cinereus at the Currumbin Wildlife Hospital Foundation in Australia (Jackson, 2018). Such initiatives span the fashion, food, beverage, sports, and automotive industries (see Supplementary Table 1 for the most recent examples of large felid NGOs partnering with corporations), and they often have win-win outcomes for both corporations and conservation NGOs.

A further example is the "Put a tiger in your tank" marketing campaign for Esso fuel, a brand name of the United States oil and gas company ExxonMobil. Esso launched the sale of fake material "tiger tails" and bumper stickers with the slogan "I've got a tiger in my tank" across the USA. They sold $\sim 2.5$ million "tails," which remain in demand to this day. After recognizing the contribution of the tiger in its marketing schemes, ExxonMobil launched the Save The Tiger Fund in 1995 in collaboration with the US National Fish and Wildlife Foundation to help preserve the tiger. Since its inception, it became an important funding body for tiger conservation projects globally and from 1995 to 2009 donated US\$ 17.3 million dollars in 336 grants (Gratwicke et al., 2007).

It is clear from the above examples (and those in Supplementary Table 1) that corporate attitudes toward nature conservation and mascot conservation may be positive. However, the partnerships we describe are often limited in their time, financial extent, and spatial coverage. There is no doubt that CSR activities like this may lead to increased financial performance (Orlitzky et al., 2003; Brammer and Millington, 2005; Campbell, 2007) and improve the social image of the corporation (Brammer and Millington, 2005). However, corporations fundamentally exist to engage in activities designed to increase their profits (Friedman, 1970), and CSR is a secondary objective. Therefore, CSR contracts between corporations and NGOs may be terminable at any time, they usually only last for a specific period and are sensitive to market forces and recessions (Reich and Wimer, 2012). For example, ExxonMobil terminated its Save The Tiger Fund after 15 years when it canceled its relationship with the US National Fish and Wildlife Foundation. Similarly, the clothing manufacturer PUMA and Tiger Beer made a one-off financial commitment to Game Rangers International in Kafue National Park, Zambia, and to the WWF, respectively, to bolster lion and tiger population recovery efforts (Wilderness Safaris, 2013). These types of donations, although important in short-term project maintenance, do not allow for long-term conservation planning and funding continuity which is key to successful species recovery programs (Crees et al., 2016). Furthermore, the objectives of potential CSR donor recipients (e.g., a conservation NGO) and corporations themselves are not always likely to align, and conservation NGOs, national governments and the species whose images are being used in marketing and media currently hold no legal right to compel a corporation to pay wildlife image royalties. There exists one pertinent question: is there a pathway for a wildlife imagery royalty scheme to be legally mandated?

\section{BACKGROUND TO ROYALTIES FOR THE ENVIRONMENT}

The fundamental premise of a royalty payment is that if an asset is sold or used by a party, a royalty payment is made to the creator or representative thereof (see https://www. copyright.gov/; accessed December 10, 2018). This can typically include copyrighted works, franchises, and natural resources. For example, the government of Western Australia mandates a mining/onshore petroleum royalty from companies extracting crude oil, and this is returned to regional projects engaging in infrastructure and community development (see https://www. agric.wa.gov.au/royalties-regions; accessed December 15, 2018). Similarly, the pharmaceutical company Merck paid advances and royalties to a Costa Rican NGO INBio for bioprospecting biological samples in Costa Rica (Zebich-Knos, 1997).

Although not explicitly a royalty, other types of fees and taxes are also used to link exploitation of wildlife to the funding of its conservation. For example, the Dingle-Johnson Act (https://www.fws.gov/laws/lawsdigest/fasport.html) employs an excise tax on fishing equipment in the USA, and this funds state-run fish management programs. Similarly, the PittmanRobertson Act places a $10-11 \%$ tax on sporting arms and ammunition to be directed toward the state-level management and restoration of wildlife. These Acts have leveraged billions of dollars for the conservation of natural resources in the USA since their inception.

\section{PAYMENTS ARE A CHALLENGE FOR EXISTING LEGAL DOCTRINE AND POLICY}

\section{Nature and Animals as Legal Persons}

Nature and environmental laws have been going through a paradigm shift over the past decade, in which rights of nature have increasingly been recognized (Charpleix, 2018). For example, "legal personhood" that businesses, trade unions, and states may all be ascribed has now been granted to rivers in New 
Zealand, glaciers and rivers in India, and more broadly to nature and the services it provides in Bolivia (Pecharroman, 2018). The recent granting of personhood to New Zealand's Whanganui River in 2017 (Charpleix, 2018) is particularly revolutionary, and after a 170-year legal battle, a treaty was signed with the local Maori tribe recognising them as legal guardians of the river. The river's interests can be protected, and New Zealand courts can award damages to a trust on behalf of the river, for instance, in response to pollution (O'Donnell and Talbot-Jones, 2018). Similarly, in 2017, the Uttarakhand High Court in India recognized the River Ganges, its glaciers, and its tributaries as a legal entity, and the high court granted the river three human representatives to conserve the river (Pecharroman, 2018).

Attempts at gaining legal personhood for non-human animals have not yet been successful. To date, there is no state or country that recognizes an animal species or an individual animal to have legal personhood. Several US courts have heard the pioneering non-human personhood cases of Steven Wise and colleagues for individual chimpanzees (Grimm, 2013) and a lone Asiatic elephant (Morris, 2018). They have, however, been unsuccessful due to a lack of subject matter jurisdiction, i.e., the power of a court to adjudicate a particular type of matter and provide the remedy demanded (Boyle, 2016; Staker, 2017). These cases have importance because legal standing is the foundation of law that allows an entity to engage copyright and intellectual property laws (e.g., USA https://www.copyright.gov/ and Australia https://www.ipaustralia.gov.aul; accessed January 10, 2019). For example, animals are unable to possess statutory standing under the United States Copyright Act (1976). Similarly, in Canada, in the case Reece v. Edmonton (City) the Alberta Court of Queen's Bench and the Alberta Court of Appeal considered the case of Lucy the elephant that was the only elephant in the Edmonton Zoo, which had a cold climate. Animal rights activists brought a case to compel her to be transferred to a sanctuary in a warmer climate with other elephants. The case was unsuccessful on the basis that animals do not have rights and the suit was found to be an abuse of process. Chief Justice Fraser, however, issued a strong dissent arguing for an expanded appreciation of animals in law, and the case Court of Appeal decision can be found at https://www.canlii.org/en/ab/abca/ doc/2011/2011abca238/2011abca238.html?searchUrlHash=AA AAAQAVZWxlcGhhbnQgRWRtb250b24gWm9vAAAAAAE\& resultIndex $=4$.

\section{Payment for Use of Property}

International copyright laws also presently bar copyright protection for works of nature (i.e., any products/creations created by non-human living organisms), requiring human authorship (e.g., Guadamuz, 2016; United States Copyright Office, 2017). Even if a member of a wildlife species manages to take selfies using complex photographic equipment like remote camera traps, they do not own the rights to those images, and cannot accrue profits from them. This is illustrated by Naruto et al v. Slater in which Petition for the Ethical Treatment of Animals (PETA) brought a suit to establish that a Celebes crested macaque Macaca nigra owned the copyright to a selfie that it took on a camera set up by Slater. Ultimately the case was dismissed and the court claimed that animals cannot hold copyrights and indicated that PETA was abusing the legal process (Guadamuz, 2016).

Even humans, who enjoy a myriad of rights, are not necessarily entitled to their right of publicity, and laws governing their voice, image, and representation are not uniform. Different jurisdictions have different rules which are largely based upon the public profile of the subject, the centrality of the person in the image (i.e., the focus or a bystander), the intended purpose of the image, whether the use is for commercial purpose, and whether any harm comes from the use of the image.

The law can ascribe rights to all kinds of entities if it finds adequate reason to do so (Chapron et al., 2019). However, given the slow progress of rights-based laws for nature, they are likely to be of little immediate use in the creation of a wildlife imagery royalty. Even if legal personhood for an individual, or an entire animal species, is granted, there is at present no legal instrument with which their human representatives can make claims under copyright or right of publicity laws on their behalf (Figure 2).

\section{ACTIONABLE RECOMMENDATIONS The Formation of National and/or International Specific Law}

States could, hypothetically, simply pass special laws that would institute royalties on businesses bearing the images of threatened wildlife species and having a negative impact on the wild populations of these species living on the territories of states. This royalty could then be paid toward the conservation of the species the businesses use (Figure 3). This is generally the domain of tort law, which requires proof of a causal connection between the claimant's injury and the actions of the defendant. Courchamp et al. (2018) hypothesized that the presentation of animal imagery creates a false perception of their abundance, which in turn induces a slackening of conservation measures. Whether this chain of causation would satisfy the legal standard of a balance of probabilities is questionable. However, if this could become a reality and if South Africa sought to employ a royalty on Lion Lager, it could seek a royalty totaling a percentage of total Lion Lager profits or sales. This funding could then be directed to either the national Ministry of Environment and national parks directly or a central clearing house represented by a reputable international conservation body (e.g., IUCN, UNEP, or UNDP). The funds could then be allocated to evidencebased conservation projects undertaking actionable conservation activities for African lion populations. These funds and actions would then be subjected to audit and assessment. This process is outlined in Figures 3, 4.

The Convention on Biological Diversity (CBD; see https://www.cbd.int/convention/articles/default.shtml?a=cbd-06; accessed November 10, 2020) counts among its objectives the conservation of biological diversity and the sustainable use of its components. Indeed, articles three, six, and eight of the CBD refer to the rights of the States to "exploit their own resources pursuant to their own environmental policies," to "develop national strategies, plans or programs for the conservation and sustainable use of biological diversity...," and to "develop or 


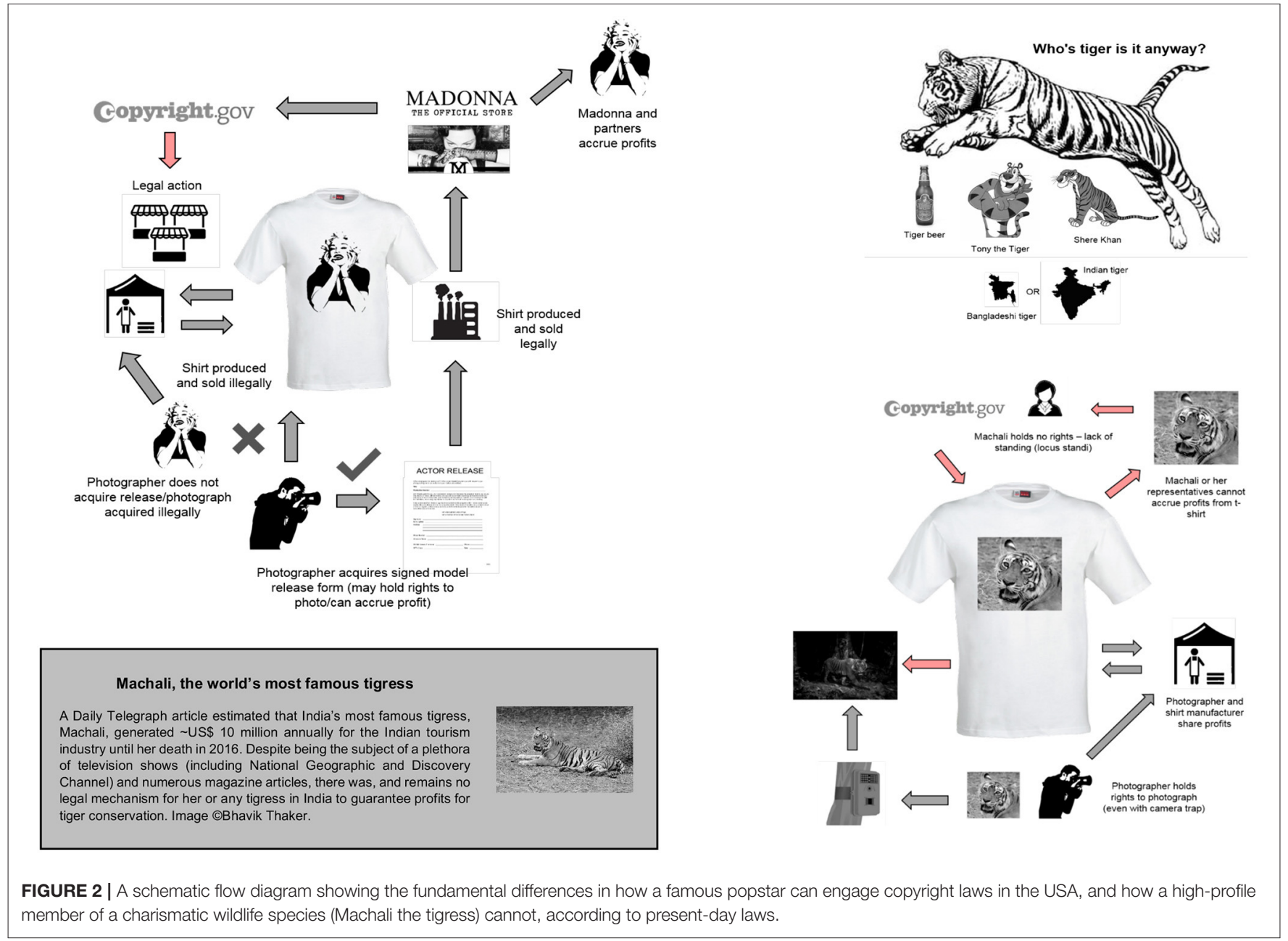

maintain necessary legislation and/or other regulatory provisions for the protection of threatened species and populations." The CBD could serve as a framework supporting the creation of a specific multilateral protocol on the matter, as it has done with the Cartagena Protocol or the Nagoya Protocol which is a global agreement that implements the access and benefitsharing obligations of the CBD. Such a protocol could require royalty payments for the use of wildlife imagery. However, legal challenges in enforcement and inter-jurisdictional cooperation are great and unlikely to work in the short to medium term. This might be avoided, however, if the country where the image is published unilaterally adopted a law requiring a fee to be paid for the publishing, and then remitted the funds to the animal country. This obviously would pose immense political challenges for implementation. For example, in the USA, the creation of a bill (and subsequent act) proved to be a successful venture for the People for the Ethical Treatment of Animals (PETA), and stakeholders interested in the welfare of the orcas Orcinus orca at SeaWorld, a large animal aquarium and theme park in San Diego, California. In 2013, the documentary film Blackfish released globally in theaters showed the challenging captive conditions several orcas faced at SeaWorld, and how a spate of attacks on aquarium workers was related to the mistreatment of the animals. This led to a public outcry that eventually assisted in the creation and passing of the Orca Welfare and Safety Act (AB1453) in the state of California in 2016. This led to the shutdown of planned expansions of orca enclosures to the value of US\$ 100 million dollars.

\section{A CONSERVATION SCHEME EQUIVALENT TO FAIRTRADE}

Another, albeit voluntary, pathway for encouraging a wildlife imagery royalty would be through the creation of a certification mark, similar to that of $1 \%$ for the Planet or Fairtrade (see Hamilton and Zilberman, 2006; Blackman and Naranjo, 2012; Blackman et al., 2014). This is a more structured approach to voluntary donations by businesses, unifying them under one collective umbrella for increased impact. Developed by American clothing manufacturer Patagonia, 1\% for the Planet encourages companies to donate $1 \%$ of their total sales to environmental causes (see http://onepercentfortheplanet.org/). To date, more than 1,800 member companies in 42 countries 


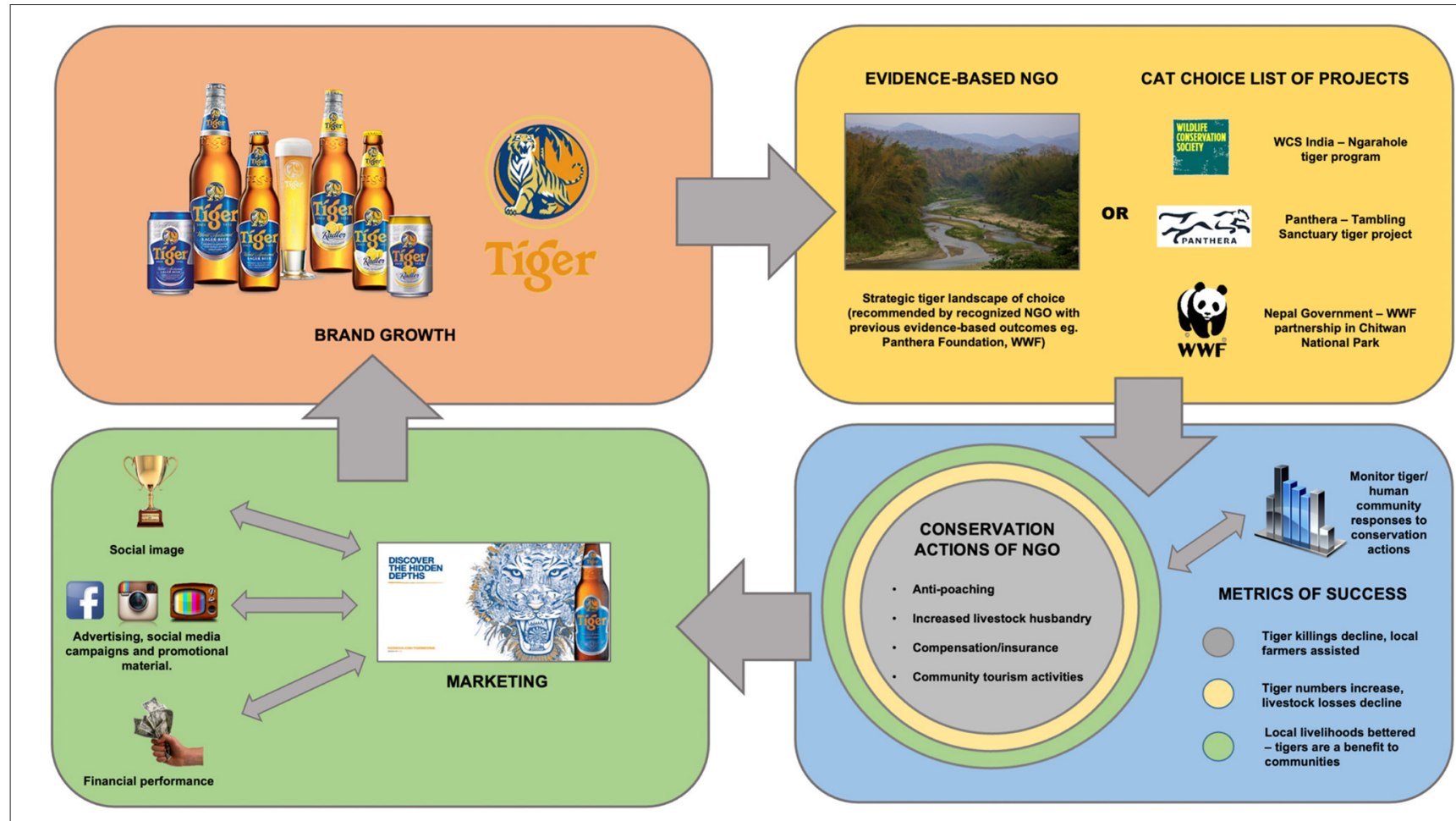

FIGURE 3 | A conceptual diagram illustrating the potential benefits from the Heineken Group's Tiger Beer for hypothetical evidence-based tiger conservation. Tiger Beer donate a percentage of their profits or sales to a strategic evidence-based project or one selected from an accredited Cats Choice List with demonstrated conservation outcomes. Funds are spent on strategic conservation interventions including anti-poaching and snaring patrols (Rabinowitz, 2009), livestock husbandry and predation deterrents, and compensation or insurance schemes (Bauer et al., 2015). Conservation actions are evaluated through monitoring of critical population parameters including density, mortality rates, birth, emigration, and immigration. Conservation successes such as a decrease in the killings of tigers, population recoveries, and a change of attitudes by local communities living alongside them are measured quantitatively. Conservation successes are reported to Tiger Beer and used in marketing channels. The CSR activity of Tiger Beer is viewed positively by both company staff and consumers of tiger beer which may, in turn, have a positive bearing on the financial performance of the company. Photograph courtesy of Steve Winter, National Geographic Magazine.

have donated US\$200 million to approve environmental conservation non-profits. These companies then advertise the $1 \%$ logo on their products, giving consumers the power to discern and make sustainable choices through their purchases. Similarly, Fairtrade provides certification to businesses engaging in more transparent, equitable trade with farmers globally. In exchange for the Fairtrade label, companies ensure that farmers receive a minimum market price for their final products and that production practices adhere to certain environmental standards (see http://www.takepart.com/flashcards/what-is-fairtrade/index.html; accessed February 7, 2019; Jaffee, 2014). Research shows that customers recognize and remember ecolabels (Sammer and Wüstenhagen, 2006), and price premiums of labeled products may increase over time (Barham and Weber, 2012). Moreover, this type of labeling may positively influence a customer's willingness to pay for a certain product, as has been shown in the appliance (Sammer and Wüstenhagen, 2006), fisheries (Teisl et al., 2002), and furniture (Veisten, 2007) industries. Because of this, the number of products awarded these types of eco-labels has grown exponentially across many industries over the past two decades (Grolleau et al., 2016). Another example (although not necessarily an example of certification) is the Lion's Share Fund (see https:// www.thelionssharefund.com, United Nations, 2018), which is a voluntary donation scheme backed by the UNDP encouraging businesses to donate $0.5 \%$ of their media budget if an animal features in their commercial. The backing of the UNDP and large brands like Gucci and Mars has garnered significant international attention (https://equilibrium.gucci.com/the-lions-share-fund/). Their objective is to raise US\$ 100 million per year for species conservation and habitat preservation.

\section{THE POTENTIAL SCALE OF A WILDLIFE IMAGERY ROYALTY: AN EXAMPLE USING LARGE FELIDS}

To assess the potential scale of a wildlife image use royalty on threatened species conservation, we examined the extent of marketing and corporate name use for just one family of charismatic species, the larger members of the Felidae (lions Panthera leo, leopards Panthera pardus, tigers Panthera tigris, jaguars Panthera onca, pumas Puma concolor, snow leopards Panthera uncia, and cheetahs Acinonyx jubatus). These species 


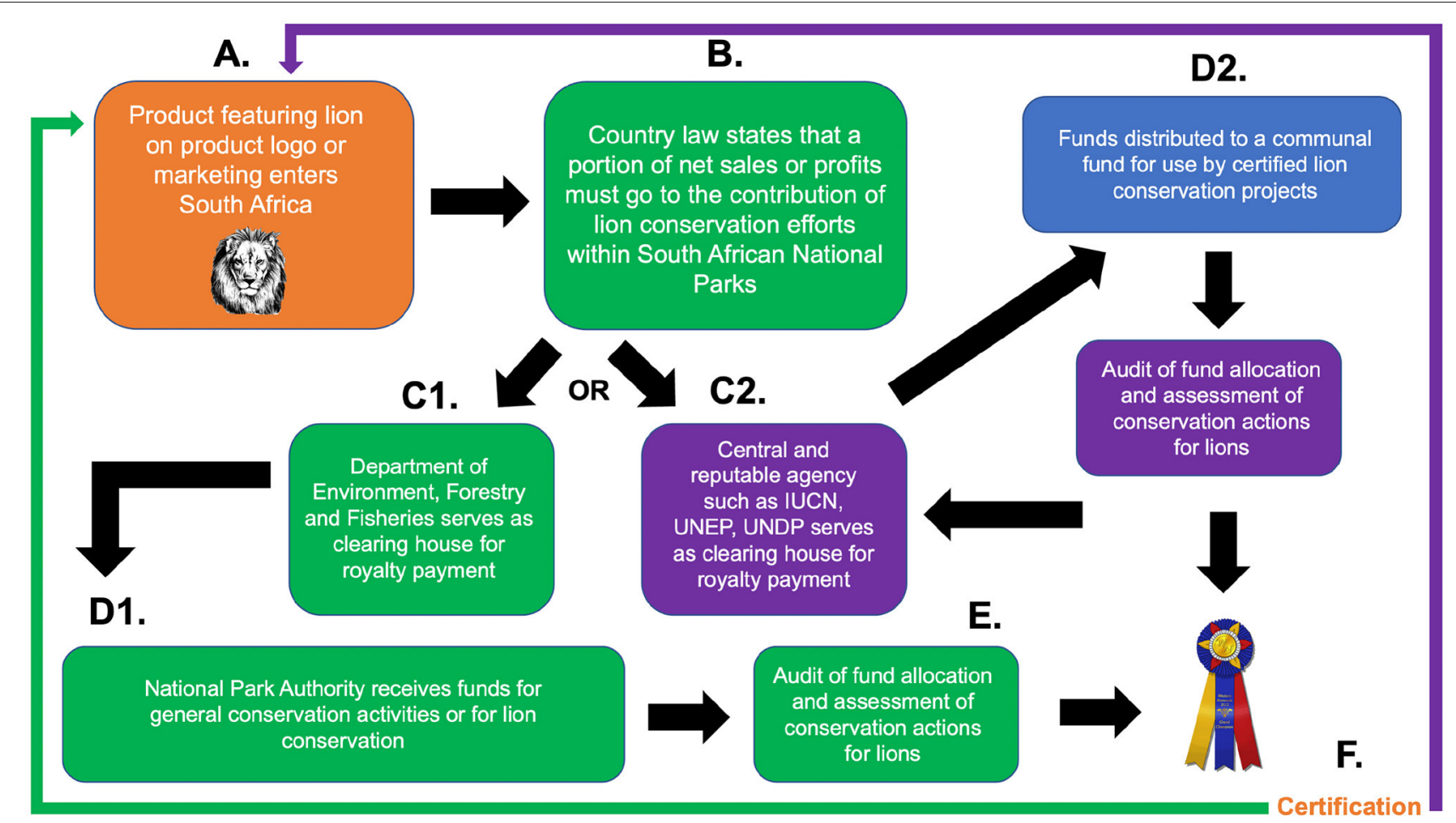

FIGURE 4 | A conceptual diagram illustrating the two paths that could channel royalty funding from a national-level law that compelled companies to pay a royalty for using an animal in their logo/branding. This funding could go to National Parks in South Africa or a central conservation agency that could serve as a clearing house for incoming funds. The process begins at point (A) when a product featuring a threatened species (in this case the African lion) enters a country with (B) a law that states a portion of net sales or profits must go toward the conservation of that species locally. Funds are then channeled to (C1) the local environment Ministry for distribution to national parks with lions, or (C2) a central conservation agency such as the IUCN, UNEP, or UNDP to serve as a central authority to distribute the funds to certified conservation projects focusing on African lions in key areas. After (D1,D2) an audit of funds is performed (E), and conservation actions assessed. Certification $\mathbf{( F )}$ is the final component of the process but can occur the moment that the company is subjected to the royalty.

are threatened across much of their range (Hunter and Barrett, 2020) and have significant top-down ecosystem and economic values (Braczkowski et al., 2018; O’Bryan et al., 2018).

We found that the use of large felids in marketing is ubiquitous, and even modest royalty payments from companies using large felids in their marketing could leverage substantial funding for conservation. For example, if the 14 companies using large felid branding on the Forbes 2000 list were to pay a royalty of $0.1-1 \%$ of profits, they would collectively leverage US $\$ 202$ million-2.02 billion annually. Even individual companies, such as Tiger Beer, could make sizeable contributions to the conservation of individual species (Supplementary Information 2 and Figure 3). The royalty margins we suggest err on the conservative side of several philanthropic initiatives. For example, the $1 \%$ for the Planet initiative donates $1 \%$ of all sales ( $1 \%$ for the Planet, 2021), Wells Fargo \& Company donates on average $1.2-1.5 \%$ annually, while Goldman Sachs donated 3\% of sales in 2015 (Preston, 2016).

A system to allocate funds generated from a royalty scheme could work via two mechanisms. First, businesses could send royalties to projects that demonstrate their conservation outcomes using evidence-based methods. There is an emerging suite of evidence-based conservation projects that address the development needs of local people and also stem the decline of the species they aim to conserve. Examples of evidencebased large felid projects include the Lion Guardians project in Kenya (Hazzah et al., 2014) and Tanzania, the Munyawana leopard program in South Africa (Balme et al., 2009), and the Cheetah Conservation Foundation's cheetah project in Namibia (Marker and Boast, 2015). Second, the funds could complement the existing voluntary Lion's Share Fund (see https://thelionssharefund.com/), which partners with companies donating a portion of their media budget, by linking to an evidence-based list of successful big cat conservation programs such as these, for which ongoing funding would otherwise be uncertain. Such projects could be a win-win for corporate partners as population recoveries are possible in some cases over just a few years (Balme et al., 2009).

\section{CATICORNS AND OTHER UNINTENDED CONSEQUENCES}

It is foreseeable that a wildlife imagery royalty could lead to a series of unintended outcomes and behaviors from both members of the public and businesses. Courchamp et al. (2018) suggested that some businesses could make small modifications to the wildlife imagery being used in their products and 
advertising, in order to avoid paying a compelled wildlife imagery royalty. If this strategy was employed by businesses at large, it could further alienate the public from wildlife and the awareness around its conservation, not just through competition for attention (Courchamp et al., 2018), but by replacing real species with fictional ones (Balmford et al., 2002). A more perverse consequence could be a selection of businesses choosing to abandon the use of any wildlife imagery (real or synthetic) in their marketing and products, taking the above example to an extreme. One way to mitigate such unintended consequences is through blockchain technology where products bearing the images of threatened wildlife are tracked through a blockchain (e.g., Howson, 2020). This could be a winwin for businesses and could be a transparent mechanism for consumers to track their investment into the species they support.

In conclusion, in this paper, we have presented possible pathways and the necessary actions required for businesses that use wildlife imagery to fund species conservation. We have shown that the funding generated from such a program could indeed be vast and important for conservation projects of threatened species. Making this operational will require actions by national governments, international NGOs, and other stakeholders. In its development, care should be taken to minimize perverse outcomes. Finally, we hope that our paper will advance the necessary thinking and legal exploration of the funding opportunities described by Good et al. (2017) and Courchamp et al. (2018).

\section{REFERENCES}

$1 \%$ for the Planet (2021). Available online at: https://www.onepercentfortheplanet. org (accessed February 5, 2021).

Balme, G. A., Slotow, R., and Hunter, L. T. (2009). Impact of conservation interventions on the dynamics and persistence of a persecuted leopard (Panthera pardus) population. Biol. Conserv. 142, 2681-2690. doi: 10.1016/j.biocon.2009.06.020

Balmford, A., Clegg, L., Coulson, T., and Taylor, J. (2002). Why conservationists should heed Pokémon. Science 295, 2367-2367. doi: 10.1126/science.295.5564.2367b

Baltz, M. E., and Ratnaswamy, M. J. (2000). Mascot conservation programs: Using college animal mascots to support species conservation efforts. Wildlife Soc. Bull. 159-163.

Barham, B. L., and Weber, J. G. (2012). The economic sustainability of certified coffee: recent evidence from Mexico and Peru. World Dev. 40, 1269-1279. doi: 10.1016/j.worlddev.2011.11.005

Bauer, H., Chapron, G., Nowell, K., Henschel, P., Funston, P., Hunter, L. T., et al. (2015). Lion (Panthera leo) populations are declining rapidly across Africa, except in intensively managed areas. Proc. Natl. Acad. Sci. U.S.A. 112, 14894-14899. doi: 10.1073/pnas.15006 64112

Blackman, A., and Naranjo, M. A. (2012). Does eco-certification have environmental benefits? Organic coffee in Costa Rica. Ecol. Econ. 83, 58-66. doi: 10.1016/j.ecolecon.2012.08.001

Blackman, A., Naranjo, M. A., Robalino, J., Alpízar, F., and Rivera, J. (2014). Does tourism eco-certification pay? Costa Rica’s blue flag program. World Dev. 58, 41-52. doi: 10.1016/j.worlddev.2013.12.002

Boyle, B. (2016). Free tilly: legal personhood for animals and the intersectionality of the civil and animal rights movements. Ind. J. Soc. Equal. 4:169.

\section{AUTHOR CONTRIBUTIONS}

$A B, J A$, and $M M$ conceived the idea. $A B$ analyzed the data. $\mathrm{AB}, \mathrm{JA}, \mathrm{MM}, \mathrm{KJ}, \mathrm{DB}$, and $\mathrm{MN}$ wrote the paper. All authors contributed to the article and approved the submitted version.

\section{FUNDING}

AB was supported by a University of Queensland graduate school scholarship (UQGSS) for the period of writing this manuscript.

\section{ACKNOWLEDGMENTS}

We thank Tad Brown from the TC Beirne School of Law (UQ); Bruce Lindsay from Environmental Justice, Australia; and Sean Maxwell and James Watson from the Center of Biodiversity and Conservation Science (UQ) for helpful comments on the manuscript. We also thank David Poulton from the Alberta Land Institute who contributed extensively to a revision of this draft but declined authorship. Rowan Eisner and Zoe Stone are thanked for their advice on the manuscript figures.

\section{SUPPLEMENTARY MATERIAL}

The Supplementary Material for this article can be found online at: https://www.frontiersin.org/articles/10.3389/fcosc. 2021.649686/full\#supplementary-material

Braczkowski, A. R., O’Bryan, C. J., Stringer, M. J., Watson, J. E., Possingham, H. P., and Beyer, H. L. (2018). Leopards provide public health benefits in Mumbai, India. Front. Ecol. Environ. 16, 176-182. doi: 10.1002/fee.1776

Brammer, S., and Millington, A. (2005). Corporate reputation and philanthropy: an empirical analysis. J. Bus. Ethics 61, 29-44. doi: 10.1007/s10551-005-7443-4

Campbell, J. L. (2007). Why would corporations behave in socially responsible ways? An institutional theory of corporate social responsibility. Acad. Manag. Rev. 32, 946-967. doi: 10.5465/amr.2007.25275684

Chapron, G., Epstein, Y., and López-Bao, J. V. (2019). A rights revolution for nature. Science 363, 1392-1393. doi: 10.1126/science.aav5601

Charpleix, L. (2018). The Whanganui River as Te Awa Tupua: place-based law in a legally pluralistic society. Geograph. J. 184, 19-30. doi: 10.1111/geoj.12238

Coad, L., Watson, J. E., Geldmann, J., Burgess, N. D., Leverington, F., Hockings, M., et al. (2019). Widespread shortfalls in protected area resourcing undermine efforts to conserve biodiversity. Front. Ecol. Environ. 17, 259-264. doi: $10.1002 /$ fee. 2042

Courchamp, F., Jaric, I., Albert, C., Meinard, Y., Ripple, W. J., and Chapron, G. (2018). The paradoxical extinction of the most charismatic animals. PLoS Biol. 16:e2003997. doi: 10.1371/journal.pbio.2003997

Crees, J. J., Collins, A. C., Stephenson, P. J., Meredith, H. M., Young, R. P., Howe, C., et al. (2016). A comparative approach to assess drivers of success in mammalian conservation recovery programs. Conserv. Biol. 30, 694-705. doi: $10.1111 /$ cobi.12652

Drucker, P. (1954). The Practice of Management. New York, NY: Harper and Row. Friedman, M. (1970). A Friedman doctrine: the social responsibility of business is to increase its profits. New York Times Magaz. 13, 32-33.

Good, C., Burnham, D., and Macdonald, D. W. (2017). A cultural conscience for conservation. Animals 7:52. doi: 10.3390/ani7070052

Gratwicke, B., Seidensticker, J., Shrestha, M., Vermilye, K., and Birnbaum, M. (2007). Evaluating the performance of a decade of Save the Tiger Fund's 
investments to save the world's last wild tigers. Environ. Conserv. 34, 255-265. doi: $10.1017 /$ S0376892907004079

Grimm, D. (2013). Animal rights: lawsuits seek 'personhood' for chimpanzees. Science 342, 1154-1155. doi: 10.1126/science.342.6163.1154

Grolleau, G., Ibanez, L., Mzoughi, N., and Teisl, M. (2016). Helping eco-labels to fulfil their promises. Clim. Policy 16, 792-802. doi: 10.1080/14693062.2015.1033675

Guadamuz, A. (2016). The monkey selfie: copyright lessons for originality in photographs and internet jurisdiction. Internet Policy Rev. 5. doi: $10.14763 / 2016.1 .398$

Hamilton, S. F., and Zilberman, D. (2006). Green markets, eco-certification, and equilibrium fraud. J. Environ. Econ. Manag. 52, 627-644. doi: 10.1016/j.jeem.2006.05.002

Hazzah, L., Dolrenry, S., Naughton, L., Edwards, C. T., Mwebi, O., Kearney, F., et al. (2014). Efficacy of two lion conservation programs in Maasailand, Kenya. Conserv. Biol. 28, 851-860. doi: 10.1111/cobi.12244

Howson, P. (2020). Building trust and equity in marine conservation and fisheries supply chain management with blockchain. Mar. Policy 115:103873. doi: 10.1016/j.marpol.2020.103873

Hunter, L., and Barrett, P. (2020). Field Guide to Carnivores of the World, Vol. 2. Bloomsbury Publishing. 46-47.

Jackson, E. (2018, May 24). Games mascot raises $\$ 100 \mathrm{k}$ for wild koalas. Brisbane Times. Brisbane.

Jaffee, D. (2014). Brewing Justice: Fair Trade Coffee, Sustainability, and Survival. Los Angeles, CA: University of California Press. doi: 10.1525/9780520957886

Jepson, P., Jennings, S., Jones, K. E., and Hodgetts, T. (2011). Entertainment value: should the media pay for nature conservation? Science 334, 1351-1352. doi: $10.1126 /$ science. 1213189

Lacoste (2018). Available online at: http://www.saveyourlogo.org/en/partners/ lacoste/ (accessed February 5, 2021).

Lindsey, P. A., Miller, J. R., Petracca, L. S., Coad, L., Dickman, A. J., Fitzgerald, K. H., et al. (2018). More than $\$ 1$ billion needed annually to secure Africa's protected areas with lions. Proc. Natl. Acad. Sci. U.S.A. 115, E10788-E10796. doi: 10.1073 /pnas. 1805048115

Marker, L. L., and Boast, L. K. (2015). Human-wildlife conflict 10 years later: lessons learned and their application to cheetah conservation. Hum. Dimens. Wildlife 20, 302-309. doi: 10.1080/10871209.2015.10 04144

McCarthy, D. P., Donald, P. F., Scharlemann, J. P., Buchanan, G. M., Balmford, A., Green, J. M., et al. (2012). Financial costs of meeting global biodiversity conservation targets: current spending and unmet needs. Science 338, 946-949. doi: $10.1126 /$ science. 1229803

Morris, A. (2018, November 19). Judge to rule on historic case of whether an elephant is a person. Forbes.

O’Bryan, C. J., Braczkowski, A. R., Beyer, H. L., Carter, N. H., Watson, J. E. M., and McDonald-Madden, E. (2018). The contribution of predators and scavengers to human well-being. Nat. Ecol. Evol. 2:229. doi: 10.1038/s41559-0170421-2

O'Donnell, E., and Talbot-Jones, J. (2018). Creating legal rights for rivers: lessons from Australia, New Zealand, and India. Ecol. Soc. 23:7. doi: 10.5751/ES-09854-230107

Orlitzky, M., Schmidt, F. L., and Rynes, S. L. (2003). Corporate social and financial performance: a meta-analysis. Organ. Stud. 24, 403-441. doi: 10.1177/0170840603024003910

Pecharroman, L. (2018). Rights of nature: rivers that can stand in court. Resources 7:13. doi: 10.3390/resources7010013
Preston, C. (2016, June 22). The 20 most generous companies of the fortune 500. Fortune.

Rabinowitz, A. (2009). Stop the bleeding: implementing a strategic tiger conservation protocol. Cat News 51, 30-31.

Reich, R., and Wimer, C. (2012). Charitable Giving and the Great Recession. Palo Alto, CA: The Russell Sage Foundation and the Stanford Center on Poverty and Inequality.

Sammer, K., and Wüstenhagen, R. (2006). The influence of eco-labelling on consumer behaviour-results of a discrete choice analysis for washing machines. Bus. Strat. Environ. 15, 185-199. doi: 10.1002/bse.522

Singh, A., and Verma, P. (2014). CSR@ 2\%: a new model of corporate social responsibility in India. Int. J. Acad. Res. Bus. Soc. Sci. 4, 455-464. doi: 10.6007/IJARBSS/v4-i10/1243

Staker, A. (2017). Should chimpanzees have standing? The case for pursuing legal personhood for non-human animals. Trans. Environ. Law 6, 485-507. doi: 10.1017/S204710251700019X

Teisl, M. F., Roe, B., and Hicks, R. L. (2002). Can eco-labels tune a market? Evidence from dolphin-safe labeling. J. Environ. Econ. Manag. 43, 339-359. doi: 10.1006/jeem.2000.1186

Tigers for Tigers. (2018). Available online at: https://www.tigersfortigers.org/ (accessed February 5, 2021).

United Nations (2018). UNDP Announces the Lion's Share Fund with Founder FINCH and Founding Partner Mars to Tackle Crisis in Wildlife Conservation and Animal Welfare. Available online at: https://www.undp.org/content/undp/ en/home/news-centre/news/2018/undp-announces-the-lion-s-share-fundwith-founder-finch-and-foun1.html (accessed February 5, 2021).

United States Copyright Act (1976). Copyright Act of 1976. Available online at: https://www.copyright.gov/title17/ (accessed February 5, 2021).

United States Copyright Office (2017). Compendium of U.S. Copyright Office Practices, $3 r d E d n$. Available online at: https://www.copyright.gov/comp3/docs/ compendium.pdf (accessed September 29, 2017).

Veisten, K. (2007). Willingness to pay for eco-labelled wood furniture: choicebased conjoint analysis versus open-ended contingent valuation. J. For. Econ. 13, 29-48. doi: 10.1016/j.jfe.2006.10.002

Waldron, A., Mooers, A. O., Miller, D. C., Nibbelink, N., Redding, D., Kuhn, T. S., et al. (2013). Targeting global conservation funding to limit immediate biodiversity declines. Proc. Natl. Acad. Sci. U.S.A. 110, 12144-12148. doi: $10.1073 /$ pnas. 1221370110

Wilderness Safaris (2013, October 14). Wilderness Safaris Joins Forces with PUMA and Panthera to bolster anti-poaching initiative in Kafue, Zambia. Wilderness Blogger.

Zebich-Knos, M. (1997). Preserving biodiversity in Costa Rica: the case of the Merck-INBio agreement. J. Environ. Dev. 6, 180-186. doi: $10.1177 / 107049659700600206$

Conflict of Interest: The authors declare that the research was conducted in the absence of any commercial or financial relationships that could be construed as a potential conflict of interest.

Copyright (C) 2021 Braczkowski, Allan, Jones, Natali, Biggs and Maron. This is an open-access article distributed under the terms of the Creative Commons Attribution License (CC BY). The use, distribution or reproduction in other forums is permitted, provided the original author(s) and the copyright owner(s) are credited and that the original publication in this journal is cited, in accordance with accepted academic practice. No use, distribution or reproduction is permitted which does not comply with these terms. 